\title{
Do Victimization Experiences Accentuate Reactions to Ostracism? An Experiment Using Cyberball
}

\author{
Sabrina Ruggieri ${ }^{\mathrm{a}, *}$, Mons Bendixen ${ }^{\mathrm{b}}$, Ute Gabriel ${ }^{\mathrm{b}}$ and Françoise Alsaker ${ }^{\mathrm{a}}$ \\ ${ }^{a}$ Department of Psychology, University of Bern, Bern, Switzerland \\ ${ }^{\mathrm{b}}$ Norwegian University of Science and Technology, Trondheim, Norway
}

\begin{abstract}
Based on the notion that the history of victimization has an impact on the sensitivity to current victimization situations this study investigated whether victims of bullying show more pronounced responses to single episodes of social exclusion. We examined whether victimization experiences in school are associated with responses to ostracism in a virtual ball tossing game (Cyberball). We compared two groups of students: 26 victims of bullying and 32 students not involved in bully/victim problems (mean age $=12.12$ ). After playing Cyberball, the victimized students in the ostracism condition scored significantly lower on feelings of meaningful existence compared to the ostracized students not involved in bully/victim problems. These results strongly support the idea that previously victimized students are more affected by experiences of social exclusion than students who are not involved in bully/victim problems.
\end{abstract}

Keywords

Cyberball, victimization, bullying, social exclusion

The experience of being victimized and systematically rejected by peers has profound consequences for the victims (Alsaker, 2012; Olweus, 1978; Perren \& Alsaker, 2006). One of the possible consequences of episodes of victimization, that has not received much attention yet, might be that victims become much more vigilant of potentially threatening situations and also show more pronounced reactions to single episodes of rejection or exclusion. This, in turn, could increase the likelihood for a previous victim to become a target of further bully attacks. Against this background, the aim of the present study was to examine whether self-reported previous victimization moderates the aversive psychological and affective consequences of a well-defined, experimentally induced episode of social exclusion. More specifically, we investigated whether students who view themselves as victims

\footnotetext{
*Address for correspondence

Sabrina Ruggieri, Department of Psychology, University of Bern, Muesmattstrasse 45, CH-3009 Bern, Switzerland. E-mail: sabrina. ruggieri@psy.unibe.ch
}

responded more negatively to being excluded from a ball-tossing game (Cyberball: Williams, Cheung, \& Choi, 2000) than their non-victimized peers.

\section{State of Research}

Bullying has been described as a subtype of aggressive behavior (Olweus, 1978; 1996), in which an individual or a group of individuals (called bullies) repeatedly and systematically attack, humiliate, or exclude a peer (called a victim) who cannot easily defend him or herself (Olweus, 1978; 1996). Bullying takes many different forms of negative actions, ranging from physical abuse (e.g., hitting, kicking) and verbal abuse (e.g., name-calling) to more subtle forms like isolation and social exclusion from a group. It has been repeatedly argued that subtle acts of aggression should always be included in the definition of bullying in order to fully grasp this phenomenon because the act of bullying is aimed at humiliating the victim and always has a psychological component (Alsaker, 2004). 
As a consequence, social exclusion is known to be a common and powerful tool to bully peers. The need to belong is central and fundamental to humans (Bastian \& Haslam, 2010; Baumeister \& Leary, 1995) and the act of being excluded from a group generates strong feelings of social pain and distress (Williams, 1997; 2001). Moreover, it is associated with depression (Gazelle \& Ladd, 2003), low self-esteem (Leary, Tambor, Terdal, \& Downs, 1995), poor academic achievement (Graham \& Juvonen, 1998), and dropping out of school (Graham \& Juvonen, 1998; Juvonen \& Gross, 2005; Rubin, Bukowski, \& Parker, 2006). The impact of social exclusion is profound and surprisingly general. In fact, experiments have shown that social exclusion threatens four fundamental needs: sense of belonging (Zadro, Williams, \& Richardson, 2004), self-esteem (Zadro et al., 2004; Williams et al., 2000), sense of meaningful existence (Williams, 2001, 2007) and control (Williams et al., 2000).

Even though social exclusion has devastating consequences for the victims, it is sometimes still dismissed as a harmless rite of passage or as an inevitable part of growing up (Alsaker, 2012). This is especially true for single incidences of social exclusion (or bullying in general), which are occasionally described as non-dramatic or even trivialized (Alsaker, 2012). However, in particular, children with a longer history of school victimization may be extremely sensitive to single episodes of exclusion. Individuals differ in how they process information about acceptance and rejection (Downey \& Romero-Canyas, 2005; Zadro, Boland, \& Richardson, 2006), and based on their previous history victims might have developed particular cognitive-affective networks (Wölfer \& Scheithauer, 2012). One such system is called the "sensitivity to rejection system" (Downey \& Feldman, 1996), which develops through a history of repeated rejection. The more frequently individuals experience victimization in social interactions, the more likely they are to incorporate the role of "victim" into their social schemas (Rosen, Milich, \& Harris, 2009), increasing the likelihood that corresponding cognitive-affective patterns of processing are activated in social situations where the issues of acceptance and rejection are of particular salience (Wölfer \& Scheithauer, 2012).

In a major study, Rosen, Milich, and Harris (2007) found that students who were identified as victims were much more likely to report frequent victimization. Moreover, a history of victimization was associated with a significantly higher degree of arousal with regard to the victimization narrative task, as well as greater difficulty in regulating emotions in high stress social situations (e.g., online ball tossing game). Rosen and colleagues (2007) concluded that victims identified with the role of victim and seemed to internalize their victimization experiences into their implicit selfconcept.

Overall, there is evidence indicating that students who have a history of victimization and students who had not been involved in bully/victim problems respond differently to social exclusion.

\section{Hypotheses}

To examine whether victims of bullying respond more sensitively to short episodes of social exclusion, we used Cyberball, an Internet ball tossing game (Williams et al., 2000) previously shown to work well in samples of early adolescents (Abrams, Weick, Thomas, Colbe, \& Franklin, 2011; Gross, 2009; Ruggieri, Bendixen, Gabriel, \& Alsaker, 2013; Sebastian, Viding, Williams, \& Blakemore, 2010).

The following hypotheses were tested: First, we expected students in the ostracism condition to report significantly lower scores on needs reflecting belonging, self-esteem, meaningful existence and control (H1a) and to be in a less positive mood at posttest compared to students in the inclusion condition (H1b). Second, within the ostracism condition, we expected the victimized students to report significantly lower scores for all four needs (H2a) and a less positive mood at posttest compared to students not involved in bully/victim problems $(\mathrm{H} 2 \mathrm{~b})$.

\section{Methods}

\section{Participants}

Participants were recruited from schools in Switzerland. The principals and teachers were asked permission to conduct the study. Upon permission from the schools, written information and letters of consent were distributed to the students' parents. All children whose parents had given their consent agreed to participate in the study. The participation rate was $72 \%$. The sample of the present study was selected from the obtained total sample of 189 students and consisted of 26 passive victims (17 girls and 9 boys) and 32 students not involved in bully/victim problems (17 girls and 15 boys) between 9 and 14 years of age $(M=12.12$, 
$S D=1.31)$. The remaining 131 students were not included in the present study because they had been categorized as bullies $(n=6)$, aggressive victims $(n=6)$, belonging to the mix category $(n=103)$ or as passive victims outside the prescribed age range $(n=16)$.

\section{Materials}

Cyberball (Williams et al., 2000). Students played Cyberball and were led to believe that they would play this "Internet ball tossing game" with two other same-sex peers taking part in the experiment. In reality, these "other children" were computer-generated confederates, who were represented by a photo of a child's face and an animated figure at the bottom of the screen. We adapted the procedure developed by Williams et al. (2000), and instructed the students in simple words to think about what kind of children they are playing with, where they are playing and how the children they play with are like (mental visualisation). Students were further instructed that when "their" figure received the ball, they had to use the mouse to indicate which of their two co-players they wanted to throw the ball to. In line with Ruggieri et al. (2013) in the ostracism condition, all students experienced inclusion first (12 ball exchanges); then they did not receive the ball anymore ( 28 ball exchanges between the other (pretended) co-players). In the inclusion condition, students and (pretended) coplayers received the ball equally often throughout the whole game.

Experiences of victimization were assessed using a validated self-report bully-victim scale (Alsaker \& Brunner, 1999; Alsaker, Nägele, Valkanover, \& Hauser, 2008). This questionnaire is very similar to the Olweus Bully/Victim Questionnaire (Olweus, 1986; 1996) and positive assessments have been made regarding the validity of self-report questionnaires (Lee \& Cornell, 2009; Olweus, 1994). The items on the self-report bully-victim scale were: "Did other students laugh at you or call you names?" "Did other students hurt you physically (e.g., hit, pinch)?" and "Did other students exclude you on purpose?" for victimization $(\alpha=0.75)$. The items to assess bullying were "Did you laugh at other students or call them names?" "Did you hurt other students physically (e.g., hit, pinch)?" and "Did you exclude other students on purpose?" $(\alpha=0.53)$. The possible responses were: 1 (never), 2 (once only), 3 (at least once a month), 4 (at least once a week), and 5 (almost every day). In line with the categorization suggested by Alsaker (2004), we coded students as passive victims if they indicated to have experienced at least one of the three items presented at least once a week over the last three months (without having been aggressive towards their peers within the last three months). Students were coded as not involved in bully/victim problems if they indicated they had never experienced any of the three items presented and had never committed any of the bullying acts. As pointed out by Alsaker (2004), this coding procedure is very rigorous and allows for the distinct identification of students as either passive victims or not involved in bully/victim problems. It was important to restrict the analyses to these two categories because the two subgroups of victims - passive victims and aggressive victims - exhibit a different behavioral pattern (Alsaker, 2004, Olweus, 1978; Perren \& Alsaker, 2006). Aggressive victims are victims who act aggressively themselves and therefore show a pattern of behavior that is typical for both victims and bullies (Alsaker, 2004; Olweus, 1978; Perren \& Alsaker, 2006). In addition, in this age group very few students report being aggressive victims (Monks, Smith, \& Swettenham, 2003).

Mood was measured using four bipolar mood items (good-bad, happy-sad, friendly-unfriendly, relaxedtense) presented with a 7-point rating scale ranging from 1 (not at all) to 7 (very much so) (Cronbach's alpha at pretest $=0.72$ and posttest $=0.76$ ). The $\operatorname{mood}$ measure was a German translation of items previously used by Gonsalkorale and Williams (2007) and had already been used in a previous study with a German sample in Switzerland (Ruggieri et al., 2013).

Need threats were measured using a 12-item questionnaire for self-reported levels of needs assessing their sense of belonging ("I felt disconnected," "I felt rejected," "I felt like an outsider"; Cronbach's alpha = 0.85), self-esteem ("I felt good about myself," "My self-esteem was high," "I felt liked"; Cronbach's alpha $=0.62$ ), sense of meaningful existence ("I felt invisible," "I felt meaningless," "I felt non-existent"; Cronbach's alpha = 0.69), and control ("I felt powerful," "I felt I had control over the course of the interaction," "I felt superior"; Cronbach's alpha $=0.49)$. These items were rated on a 5-point scale ranging from 1 (not true) to 5 (very much true). Also, these items were a German translation of the items previously used by Gonsalkorale and Williams (2007), which had been used earlier (Ruggieri et al., 2013).

\section{Procedure}

The participants were randomly assigned to either the ostracism condition or the inclusion condition. The 
students were tested individually in a single session and in a separate room in their school. A research assistant was present during the entire session to answer any questions. Before playing the Cyberball game on a computer, the students provided personal information regarding their date of birth, sex and current mood. Immediately after playing the game, students completed a questionnaire covering the same four mood items as at pretest, twelve items on self-reported levels of need and six items from a self-report bully/victim scale (Alsaker \& Brunner, 1999; Alsaker et al., 2008). Finally, to check whether the manipulation had the intended effect, participants were asked "How often did you get the ball?" and "To what extent were you included by the other participants during the game?" using a 4-point rating scale ranging from 1 (not at all) to 4 (very much so), as well as to indicate the extent to which they felt rejected (1) or accepted (9) using a 9-point scale.

Upon completion of the questionnaire, the students were thanked and debriefed. The debriefing consisted of verbal information about the randomized allocation of the participants to the inclusion and ostracism condition. Students were told that they were playing the game with two computer-generated confederates. For ethical reasons, students who were assigned to the ostracism condition were invited to play Cyberball in an inclusion condition before leaving. All students accepted the invitation. The research assistant made sure that the students understood the difference between the two conditions. At the end, the students received a small gift (a yoyo-game) in exchange for their participation in the study. The study was approved by the ethical committee of the Faculty of Human Sciences, University of Bern.

\section{Results}

From the sample of 58 students, 31 students were assigned to the ostracism condition ( 20 girls, 11 boys) and 27 students to the inclusion condition (14 girls, 13 boys). The percentage of passive victims and students not involved in bully/victim problems did not differ between the ostracism and inclusion condition, $\chi^{2}(1, N=58)=1.24, p=0.27$. Of the passive victims, 16 students were in the ostracism condition and 10 students were in the inclusion condition. Of the students not involved in bully/victim problems, 15 students were in the ostracism condition and 17 students were in the inclusion condition.
To test whether the ostracism manipulation was effective, we performed three ANOVAs comparing the ostracized and included students. Students correctly perceived whether they were excluded or included in the game. Students in the ostracism condition $(M=2.39$, $S D=0.76)$ reported to have received the ball significantly less often, $F(1,56)=23.46, p<0.001$, partial $\eta^{2}=0.29$ than students in the inclusion condition $(M=3.22, S D=0.50)$.

Furthermore, students in the ostracism condition $(M=2.52 S D=0.77)$ reported feeling more excluded than students in the inclusion condition $(M=3.48, S D$ $=0.50), F(1,56)=30.76, p<0.001$, partial $\eta^{2}=0.36$, and students in the ostracism condition $(M=6.10$, $S D=2.43$ ) felt more rejected than students in the inclusion condition $(M=8.11, S D=1.01), F(1,56)=16.12$, $p<0.001$, partial $\eta^{2}=0.22$.

\section{Mood at Pre- and Posttest}

To test whether the mood levels differed for the ostracized and included students, we performed two 2 (condition: included vs. ostracized) $\times 2$ (victimization: victim vs. non-involved) ANOVAs (see Table 1 for means and SD). Mood level at pretest did not differ between students in the ostracism vs. inclusion condition, $F(1,54)<1$. There was however a significant main effect of victimization, $F(1,54)=9.67$, $p<0.05$, partial $\eta^{2}=0.15$, indicating that the passive victims' mood was significantly lower than the mood of students not involved in bully/victim problems. The interaction effect condition $\times$ victimization was not significant $F(1,54)=1.22, p=0.27$. For $\operatorname{mood}$ at posttest, both experimental condition, victimization status and their interaction became significant: Students in the ostracism condition reported a significantly lower mood at posttest compared to students in the inclusion condition, $F(1,54)=6.22, p<0.05$, partial $\eta^{2}=0.10$, and the passive victims reported a lower mood, $F(1,54)=12.60, p<0.05$, partial $\eta^{2}=0.19$, compared to students who were not involved in bully/victim problems. Furthermore, follow up analysis on the significant victimization $\times$ condition interaction effect, $F(1,54)=4.62, p<0.05$, partial $\eta^{2}=0.08$, indicated that passive victims showed a significantly lower mood than the non-involved students in the ostracism condition, $F(1,54)=18.1, p<0.001$, partial $\eta^{2}=0.25$, but not in the inclusion condition, $p=0.35$ (see Table 1 for means and SD). 
Table 1

Means and Standard Deviations (SD) for Mood and Needs Separately in the Inclusion and Ostracism Condition

\begin{tabular}{|c|c|c|c|c|c|c|c|}
\hline \multirow[t]{2}{*}{ Condition } & \multirow[t]{2}{*}{ Victimization } & \multicolumn{2}{|c|}{ Mood } & \multicolumn{3}{|c|}{ Needs } & \multirow[b]{2}{*}{ Control } \\
\hline & & $\begin{array}{l}\text { Mood } \\
\text { at pretest }\end{array}$ & $\begin{array}{c}\text { Mood } \\
\text { at posttest }\end{array}$ & $\begin{array}{c}\text { Sense of } \\
\text { belonging }\end{array}$ & Self-esteem & $\begin{array}{c}\text { Sense of } \\
\text { meaningful existence }\end{array}$ & \\
\hline \multirow{3}{*}{$\begin{array}{l}\text { Inclusion } \\
\text { condition }\end{array}$} & Not involved & $6.25(0.538)$ & $6.37(0.626)$ & $1.22(0.352)$ & $2.98(0.640)$ & $1.39(0.517)$ & $2.51(0.393)$ \\
\hline & Passive victims & $5.80(0.888)$ & $6.03(0.885)$ & $1.40(0.584)$ & $3.00(0.737)$ & $1.50(0.689)$ & $2.53(0.571)$ \\
\hline & Total & $6.08(0.707)$ & $6.24(0.735)$ & $1.28(0.450)$ & $2.99(0.663)$ & $1.43(0.576)$ & $2.12(0.456)$ \\
\hline \multirow{3}{*}{$\begin{array}{l}\text { Ostracism } \\
\text { condition }\end{array}$} & Not involved & $6.38(0.533)$ & $6.28(0.632)$ & $1.98(0.850)$ & $2.84(0.616)$ & $1.93(0.594)$ & $2.71(0.689)$ \\
\hline & Passive victims & $5.44(1.21)$ & $4.89(1.31)$ & $2.83(0.807)$ & $2.42(0.694)$ & $2.77(0.540)$ & $2.29(0.824)$ \\
\hline & Total & $5.90(1.05)$ & $5.56(1.24)$ & $2.42(0.923)$ & $2.62(0.681)$ & $2.37(0.701)$ & $2.49(0.779)$ \\
\hline
\end{tabular}

Note: For "sense of belonging" and "sense of meaningful existence," higher values indicate lower sense of belonging and lower sense of meaningful existence.

\section{Self-Reported Levels of Needs at Posttest}

To test if sense of belonging, self-esteem, sense of meaningful existence, and control differed for passive victims and students not involved in bully/victim problems, we performed four 2 (condition: included vs. ostracized) $\times 2$ (victimization: victim vs. non-involved) ANOVAs (see Table 1 for mean and SD). On average, students in the ostracism condition reported scores indicating feelings of less belonging, $F(1,54)=36.25$, $p<0.001$, partial $\eta^{2}=0.40$, lower self-esteem, $F(1$, $54)=4.05, p<0.05$, partial $\eta^{2}=0.07$ and feelings of less meaningful existence, $F(1,54)=34.46, p<0.001$, partial $\eta^{2}=0.39$, compared to students in the inclusion condition. Students in the ostracism condition did not differ from students in the inclusion condition in terms of control, $F(1,54)<1$. After playing Cyberball, the passive victims reported scores indicating feelings of less belonging, $F(1,54)=8.13, p<0.05$, partial $\eta^{2}=0.13$, and feelings of less meaningful existence, $F(1,54)=9.38, p<0.05$, partial $\eta^{2}=0.15$, compared to not involved students. Regarding feelings of "meaningful existence" a significant victimization $\times$ condition interaction effect, $F(1,54)=5.59, p<0.05$, partial $\eta^{2}=0.09$ emerged. Follow up analysis revealed that passive victims scored significantly lower on feelings of "meaningful existence" compared to not involved students in the ostracism condition $F(1,54)=16.41, p<0$. 001 , partial $\eta^{2}=0.23$, but not in the inclusion condition $F(1,54)<1$.

\section{Discussion}

Based on the notion that the history of victimization has an impact on the sensitivity to current victimization situations we expected victims of bullying to show more pronounced responses to single episodes of social exclusion. More specifically, we examined whether self-reported victimization moderates the aversive psychological (need-threat) and affective (mood) consequences of an experimentally induced episode of exclusion. The findings of the present study replicate and extend previous results. In line with previous research we found that short episodes of a laboratorybased exclusion experience have an adverse affect on mood and primary needs (for a review, see Williams, 2001) in early adolescents (Abrams et al., 2011; Gross, 2009; Ruggieri et al., 2013; Sebastian et al., 2010; Wölfer \& Scheithauer, 2012). Extending previous research, the most important finding of the current study was that victims of bullying responded more sensitively to being excluded in terms of lower mood levels and feelings of less meaningful existence.

Meaningful existence is about feeling that one's life has a purpose and that this purpose is recognized by others. Compared to self-esteem, i.e., how one feels about oneself, meaningful existence focuses more on the mechanisms through which these feelings are formed. The items assessing meaningful existence may therefore better capture the core issue of social exclusion as well as the central mechanism of bullying in general. Psychological well-being is at least partly dependent on the perception that one is valued by others (Pyszeczynsky, Greenberg, \& Solomon, 1997). Therefore, the well-being of victims may be especially disturbed by systematic and repeated bullying attacks. In fact, Alsaker (2012) has argued that the discrepancy victims perceive between their suffering and the trivialization expressed by others triggers feelings of not being a valuable person, or as Williams puts it, not having a meaningful existence (Williams, 2001). This experimental study lends support to these assumptions by showing that the perceptions and feelings of victims are profoundly damaged and that their negative feelings may be easily activated even in virtual ostracism situations. 
Mood was also more affected from short episodes of social exclusion in students who view themselves as passive victims. Unexpected events can influence mood. Individuals differ however in how easily their mood is affected through such events. Mood is generally less affected in adults (Twenge, Baumeister, Tice, \& Stucke, 2001; Zadro et al., 2004) and adults have also been described as more stable compared to children and adolescents (Larcom \& Isaacowitz, 2009) indicating that self-confidence and stability might moderate the impact of unexpected events on mood. This in turn might explain, why passive victims, who seem to be generally less self-confident and less stable (Alsaker, 2006; Boulton \& Smith, 1994) are more strongly affected by negative events.

Our study is the first to show a different psychological response after short episodes of exclusion depending on one's bully/victim status. In general our findings suggest that being victimized may bias how subsequent exclusion situations are interpreted and being victimized may be associated with lower rates of recovery (because the devastating episodes are experienced repeatedly). In a similar vein, Zadro and colleagues (2006) reported that highly anxious adults (mean age 22 years) recovered more slowly from the effects of exclusion compared to non-anxious participants.

\section{Implications}

The cognitive-affective network seems to play an important role in understanding the negative adjustment of victims. In line with the finding that frequently experienced victimization might lead to incorporating the role of "victim" into one's social schemas (Rosen et al., 2009), our results showed that students who perceive themselves as victims responded more intensively to a short episode of social exclusion. This finding has important implications for handling bullying. Single episodes of victimization that might seem harmless for teachers and for other students, would activate the cognitive-affective network in the victim who perceives the "minor incidence" more negatively. Consequently single incidences of victimization should be seen as adding burden to a history of victimization. It often happens that victims of bullying change class or even school. However, our results suggest that changing the situation might not be the appropriate action. The history of victimization remains unchanged and the cognitive-affective networks of victims might put them at risk to become a victim in a new situation.
Today, researchers agree that bullying constitutes a serious risk with respect to the psychological, social and academic adjustment of victims (Buhs, Ladd, \& Herald, 2006; Hawker \& Boulton, 2000). Overall, the present study has demonstrated that although the aversive experience of exclusion may be universal, whether or not we recover from the experience may be moderated by victimization history. Given the detrimental consequences of ostracism, those who are vulnerable or particularly susceptible to ostracism (e.g., victims of bullying) need to be identified early in order 1) to stop the victim's suffering, and 2) to stop negative cycles of exclusion, interpretations, and expectations.

Previous studies have found that many teachers ignore and passively support bullying behaviors (Alsaker, 2012; Salmivalli, 2010; Stassen Berger, 2007). It is possible that teachers do not recognize the severity of bullying. In fact, Cohn and Canter (2002) reported that $25 \%$ of teachers see nothing wrong in bullying and intervene in only $4 \%$ of bullying incidents. Likewise, teachers often indicate that they intervene if they perceive the situation as serious (Newman, 2011). In fact, acknowledging the severity of bullying is the basic assumption for keeping the eyes open. Unless bullying is acknowledged as disrespectful and unfair, teachers (and other witnesses) will not be motivated to recognize bullying and implement intervention measures. In summary, teachers first need to recognize the severity of bullying and the significance that a single incidence represents for the victims in order to recognize it when it happens and take responsible actions to stop it. Our results emphasize that taking single episodes seriously may be especially important for victims of bullying who already show a history of rejection and exclusion.

Second, social exclusion is a common and powerful form of bullying and differs from other forms of bullying. It is comparatively subtle to exclude someone from a social activity (e.g., by saying "you can't play, this game is only played by three people"). Furthermore, social exclusion can be easily reframed. In the example mentioned above, one could simply refer to the rules of the game instead of intending to do harm. Unfortunately, due to the lack of visible scars in social exclusion, people often think that the victim is exaggerating since there is no visible trail for others to follow (Alsaker, 2012; Nordgren, Banas, \& MacDonald, 2011). However, researchers agree that it is not necessary to be physically harmed in order to suffer lasting harm (Alsaker, 2012; Nordgren et al., 2011). Social exclusion is not always included in the research 
on bullying and may even be given less importance compared to direct forms of bullying (e.g., pushing, hitting, verbal bullying) (Alsaker \& Valkanover, 2001).

\section{Strengths and Limitations}

One strength of the study is the rigorous use of the bully/victim concept. We refrained from mixing aggressive and passive victims and were rigorous in the determination of the cut-off point. A major strength of the study is clearly the experimental design in studying the immediate outcome of a situation of social exclusion. The Cyberball paradigm is an appealing tool because it captures the essence of the ball-tossing game without having to use or engage in the time consuming training of confederates (Williams \& Jarvis, 2006); in addition, it has been shown to work well in this age group of early adolescents (Gross, 2004; Ruggieri et al., 2013). However our procedure differs slightly from that used e.g. by Abrams et al., 2011 and Sebastian et al., 2010 in that the participants received the ball more often before the exclusion episode started, and the total length of the episode was shorter.

The small sample size with a relatively large age span and the cross-sectional design are limitations of the present study. Moreover, it should be taken into account that we did not use a baseline measure of the four needs (as was done for the mood measure) and therefore could not assess whether the victims differed from the not involved students prior to playing the game on these needs. In addition, different measures from the ones suggested by Williams (2001) may be used in future studies. Moreover all measurements were gathered during a single session. Future studies would be advised to performing pre-and posttests of need threats.

\section{References}

Abrams, D., Weick, M., Thomas, D., Colbe, H., \& Franklin, K. M. (2011). On-line ostracism affects children differently from adolescent and adults. British Journal of Developmental Psychology, 29, 110-123.

Alsaker, F. D. (2004). Quälgeister und ihre Opfer. Mobbing unter Kindern und wie man damit umgeht [Bullies and their victims. How to cope with bullying in childhood]. Bern, Switzerland: Huber Verlag.

Alsaker, F. D. (2012). Mutig gegen Mobbing in Kindergarten und Schule [Taking Action against bullying in kindergarten and school]. Bern, Switzerland: Huber Verlag.
Alsaker, F. D., \& Brunner, A. (1999). Switzerland. In P. Smith, K. Morita, J. Junger-Tas, D. Olweus, R. Catalano, \& P. Slee (Eds.), The nature of school bullying: A cross-national perspective (pp. 250-263). London: Routledge.

Alsaker, F. D., Nägele, C., Valkanover, S., \& Hauser, D. (2008). Pathways to victimization and a multisetting intervention: Project documentation. Bern, Switzerland: University of Bern.

Alsaker, F. D., \& Valkanover, S. (2001). Early diagnosis and prevention of victimization in kindergarten. In J. Juvonen, \& S. Graham (Eds.), Peer harrassment in school: The plight of the vulnerable and victimized (pp. 175-195). New York, NY: Guildford Press.

Bastian, B., \& Haslam, N. (2010). Excluded form humanity: The dehumanizing effects of social ostracism. Journal of Experimental Social Psychology, 46, 107-113.

Baumeister, R. F., \& Leary, M. R. (1995). The need to belong: Desire for interpersonal attachment as a fundamental human motivation. Psychological Bulletin, 117, 497-529.

Boulton, M. J., \& Smith, P. K. (1994). Bully/victim problems in middle-school children: Stability, self-perceived competence, peer perceptions and peer acceptance. British Journal of Developmental Psychology, 12, 315-329.

Buhs, E. S., Ladd, G. W., \& Herald, S. L. (2006). Peer exclusion and victimization: Processes that mediate the relation between peer group rejection and children's classroom engagement and achievement? Journal of Educational Psychology, 98, 1-13.

Downey, D., \& Feldman, S. (1996). Implications of rejection sensitivity for intimate relationships. Journal of Personality and Social Psychology, 70, 1327-1343.

Downey, D., \& Romero-Canyas, R. (2005). Rejection sensitivity as a predictor of affective and behavioral responses to interpersonal stress: A defensive motivational system. In K. D. Williams, J. P. Forgas, \& W. Von Hippel (Eds.), The social outcast: Ostracism, social exclusion, rejection and bullying (pp. 131-154). New York, NY: The Psychology Press.

Gonsalkorale, K., \& Williams, K. B. (2007). The KKK won't let me play: Ostracism even by a despised outgroup hurts. European Journal of Social Psychology, 37, 1176-1186.

Graham, S., \& Juvonen, J. (1998). Self-blame and peer victimization in middle school: An attributional analysis. Developmental Psychology, 34, 587-538.

Gross, E. F. (2004). Adolescent internet use: What we expect, what teens report. Journal of Applied Developmental Psychology, 25, 633-649.

Gross, E. F. (2009). Logging on, bouncing back: An experimental investigation of online communication following social exclusion. Developmental Psychology, 45, 1787-1793.

Hanish, L. D., \& Guerra, N. G. (2002). A longitudinal analysis of patterns of adjustment following peer victimization. Development and Psychopathology, 14, 69-89.

Hawker, D. S., \& Boulton, M. J. (2000). Twenty years' research on peer victimization and psychological maladjustment: A metaanalytic review of cross-sectional studies. Journal of Child Psychology and Psychiatry, 41, 441-455.

Hodges, E. V., \& Perry, D. G. (1999). Personal and interpersonal antecedents and consequences of victimization by peers. Journal of Personality and Social Psychology, 76, 677-685.

Juvonen, J., \& Gross, E. F. (2005). The rejected and the bullied: Lessons about social misfits from developmental psychology. In K. D. Williams, J. P. Forgas, \& W. Hippel (Eds.), The social outcast: Ostracism, social exclusion, rejection, and bullying (pp. 155-170). New York, NY: Psychology Press. 
Larcom, M. J., \& Isaacowitz, D. M. (2009). Rapid emotion regulation after mood induction: Age and individual differences. The Journal of Gerontology: Series B, 64B(6), 733-741.

Leary, M. R., Tambor, E. S., Terdal, S. K., \& Downs, D. L. (1995). Self-esteem as an interpersonal monitor: The sociometer hypothesis. Journal of Personality and Social Psychology, 68, 518-530.

Monks, C., Smith, P. K., \& Swettenham, J. (2003). Aggressors, victims, and defenders in preschool. Peer, self-, and teacher reports. Merril Palmer Quarterly, 49, 453-469.

Newman, J. B. (2011). Teacher interventions in bullying situations: Perceptions of middle school students and teachers. Dissertation Abstracts International Section A: Humanities and Social Sciences, 71(10A), 3529.

Nordgren, L. F., Banas, K., \& MacDonald, G. (2011). Empathy gaps for social pain: Why people underestimate the pain of social suffering. Journal of Personality and Social Psychology, 100, $120-128$.

Olweus, D. (1978). Aggression in the schools: Bullies and whipping boys. Washington, DC: Hemisphere.

Olweus, D. (1996). Bullying at school: Knowledge base and an effective intervention program. In C. Ferris, \& T. Grisso (Eds.), Understanding aggressive behavior in children (pp. 265-276). New York, NY: New York Academy of Science.

Perren, S., \& Alsaker, F. D. (2006). Social behavior and peer relationships of victims, bully-victims, and bullies in kindergarten. Journal of Child Psychology and Psychiatry, 47, 45-57.

Pyszczynski, T., Greenberg, J., \& Solomon, S. (1997). Why do we need what we need? A terror management perspective on the roots of human social motivation. Psychological Inquiry, 8, 1-20.

Rosen, P. J., Milich, R., \& Harris, M. J. (2007). Victims of their own cognitions: Implicit social cognitions, emotional distress, and peer victimization. Journal of Applied Developmental Psychology, 28, 211-226.

Rosen, P. J., Milich, R., \& Harris, M. J. (2009). Why's everybody always picking on me?: Social cognition, emotional regulation, and chronic peer victimization in children. In M. J. Harris (Ed.), Bullying, rejection, and peer victimization: A social cognitive neuroscience perspective (pp. 79-100). New York, NY: Springer.

Rubin, K. H., Bukowski, W., \& Parker, J. G. (2006). Peer interactions, relationships, and groups. In N. Eisenberg, W. Damon \& R. M. Lerner (Eds.), Handbook of Child Psychology: Vol. 3, Social, emotional, and personality development (6th ed., pp. 571-645). New York, NY: Wiley.

Ruggieri, S., Bendixen, M., Gabriel, U., \& Alsaker, F. D. (2013). Cyberball: The impact of ostracism on the well being of adolescents. Swiss Journal of Psychology, 72, 103-109.

Salmivalli, C. (1999). Participant role approach to school bullying: Implications for intervention. Journal of Adolescence, 22, 453459.

Salmivalli, C. (2010). Bullying and the peer group: A review. Aggression and Violent Behavior, 15, 112-120.

Sebastian, C., Viding, E., Williams, K. D., \& Blakemore, S.- J. (2010). Social brain development and the affective consequences of ostracism in adolescence. Brain and Cognition, 72, 134-145.

Stassen Berger, K. (2007). Update on bullying at school: Science forgotten. Developmental Review, 27, 90-126.
Sutton, J., \& Smith, P. K. (1999). Bullying as a group process. An adaption of the participant role approach. Aggressive Behavior, 25, 97-111.

Twenge, J. M., Baumeister, R. F., Tice, D. M., \& Stucke, T. S. (2001). If you can't join them, beat them. Effects of social exclusion on aggressive behavior. Journal of Personality and Social Psychology, 81, 1058-1069.

Williams, K. D. (1997). Social ostracism. In R. M. Kowalski (Ed.), Aversive interpersonal behaviors (pp. 133-170). New York, NY: Plenum.

Williams, K. D. (2001). Ostracism: The power of silence. New York, NY: Guildford Press.

Williams, K. D. (2007). Ostracism. Annual Review of Psychology, $58,425-452$.

Williams, K. D., Cheung, C. K. T., \& Choi, W. (2000). Cyberostracism: Effects of being ignored over the internet. Journal of Personality and Social Psychology, 79, 748-762.

Williams, K. D., \& Jarvis, B. (2006). Cyberball: A program for use in research on interpersonal ostracism and acceptance. Behavior Research Methods, 38, 174-180.

Wölfer, R. \& Scheithauer, H. (2012). Ostracism in childhood and adolescence: Emotional, cognitive, and behavioral effects of social exclusion. Social Influence, 1-20 (i-first) DOI: $10.1080 / 15534510.2012 .706233$

Zadro, L., Boland, C., \& Richardson, R. (2006). How long does it last? Persistence of the effects of ostracism in the socially anxious. Journal of Experimental Social Psychology, 42, 692-697.

Zadro, L., Williams, K. B., \& Richardson, R. (2004). How low can you go? Ostracism by a computer is sufficient to lower selfreported levels of belonging, control, self-esteem, and meaningful existence. Journal of Experimental Social Psychology, 40, 560567.

\section{Bio Sketches}

Françoise D. Alsaker is a Professor for Developmental Psychology at the University of Berne, Switzerland. In the last decade, her research has focused on victimization and its prevention through kindergarten and primary school.

Mons Bendixen is associate professor in social psychology at NTNU. He publications cover sexual harassment, sexual abuse, bullying, ostracism and antisocial behavior. In recent years his research has been done increasingly within the evolutionary psychology paradigm focusing on sexual strategies and mating tactics.

Ute Gabriel is professor in social psychology at NTNU, Norway. Prior to coming to NTNU, she had been a lecturer at the Chair of Social Psychology and Psychology of Law at the University of Berne (Switzerland). She did her doctorate work at the Criminological Research Institute of Lower Saxony (Hannover, Germany) on the effects of criminal victimization on individual's fear of crime and punitiveness.

Sabrina Ruggieri is a PhD Student in Developmental Psychology at the University of Berne (Switzerland). Her research interests include victimization, peer exclusion, and peer relationships in childhood and adolescence. 